\title{
Integration of accelerated precipitation softening with membrane distillation for high-recovery desalination of primary reverse osmosis concentrate
}

\author{
Dan $\mathrm{Qu}^{\mathrm{a}}$, Jun Wang ${ }^{\mathrm{a}, *}$, Longlong Wang ${ }^{\mathrm{b}}$, Deyin Hou ${ }^{\mathrm{a}}$, Zhaokun Luan ${ }^{\mathrm{a}}$, Baoqiang Wang ${ }^{\mathrm{b}}$ \\ a State Key Laboratory of Environmental Aquatic Chemistry, Research Center for Eco-Environmental Sciences, The Chinese Academy of Sciences, Beijing 100085, China \\ ${ }^{\mathrm{b}}$ School of Chemical and Environmental Engineering, China University of Mining-Technology, Beijing 100083, China
}

\section{A R T I C L E I N F O}

\section{Article history:}

Received 4 November 2008

Received in revised form 19 February 2009

Accepted 28 February 2009

\section{Keywords:}

Direct contact membrane distillation

Accelerated precipitation softening

Primary reverse osmosis concentrate

High-recovery desalination

\begin{abstract}
A B S T R A C T
Accelerated precipitation softening (APS) was integrated with direct contact membrane distillation (DCMD) to establish a desalination process for high-recovery desalting of primary reverse osmosis (PRO) concentrate. The APS process, between the PRO concentrate and the DCMD process, involved pH adjustment with sodium hydroxide along with calcite seeding, followed by microfiltration to avoid seeds clogging of the DCMD module. The PRO concentrate was obtained from the RO process of the direct drinking water preparation system designed for the 29th Olympic Games with 50\% recovery. pH adjustment to $10.10,5 \mathrm{~g} / \mathrm{L}$ calcite dosage and $200 \mathrm{r} / \mathrm{min}$ agitation rate was determined for APS treatment via initial small-scale calcium removal tests. Elemental analysis revealed that APS treatment enabled 92\% removal of calcium, $58.4 \%$ removal of total hardness, $4.4 \%$ removal of magnesium, $1.1 \%$ removal of sulfate and $1.6 \%$ removal of silica. Compared with the sharp decline found in the DCMD process of the PRO concentrate, the permeate flux declined only $20 \%$ within $300 \mathrm{~h}$ running after APS treatment. Then the PRO concentrate was concentrated 40 times and the whole recovery was enhanced to $98.8 \%$. The permeate conductivity varied between 2.0 and $4.0 \mu \mathrm{S} / \mathrm{cm}$ during the DCMD process, and slightly increased to $6.0 \mu \mathrm{S} / \mathrm{cm}$ at the end due to partial wetting phenomenon.
\end{abstract}

(C) 2009 Elsevier B.V. All rights reserved.

\section{Introduction}

In recent years, reverse osmosis desalination has been explored as a viable technology for desalination of brackish water for industrial and civil use [1-6]. However, membrane scaling $\left(\mathrm{CaCO}_{3}\right.$, $\mathrm{CaSO}_{4}$, etc.) reduces membrane productivity and forces operation at lower than optimal recovery level, thereby increasing concentrate production [7]. Each year, a large amount of RO concentrate discharges and leads to a significant loss of water resource and disposal challenge. As a consequence, concentrate minimization is essential for many countries to alleviate environmental challenge [8].

Currently, the available method to improve RO recovery is using water soluble polymeric antiscalants. It can suppress mineral salt precipitation to some extent. However, even with the use of antiscalants, mineral salt scaling remains an impediment to achieving high product water recovery, partially due to the increased potential of fouling when excessive dose of antiscalants is applied [9].

Another possible approach to improve RO recovery is to utilize an accelerated precipitation process to remove scaling ions before RO process [10]. Conventional precipitation is to induce cal-

\footnotetext{
* Corresponding author. Tel.: +8610 62849198; fax: +86 1082849198 .

E-mail address: junwang@rcees.ac.cn (J. Wang).
}

cium carbonate crystallization through chemical dosing (e.g. lime, caustic, and soda ash) [11,12]. However, the produced calcium carbonate crystals require a long time (about $1.5-3 \mathrm{~h}$ ) to settle and result in low content solid (2-30\%) [11]. Due to the above drawbacks, seeded precipitation has been developed. It can provide a preferential surface area for heterogeneous nucleation and growth of mineral salts. Thus, the precipitation kinetics and the efficiency of solid-liquid separation can be significantly improved [13-15]. Various seeded precipitation softening for RO process pretreatment were reported in the literature. Rahardianto et al. [16] integrated RO and APS for high water recovery desalting of mildly brackish water, and the results indicated that the recovery up to $98 \%$ is feasible with the PRO-APS-SRO sequence. In a compact accelerated precipitation softening (CAPS) proposed by Gilron et al. [17] for RO pretreatment of surface water, CAPS allowed high RO recoveries by reducing the scaling potential and also reduced the contaminant load of colloids, dissolved organics microorganisms. In addition, Gilron et al. [18] compared CAPS and conventional media filtration in brackish water RO process, and concluded that CAPS allowed stable operation at higher recovery than conventional media filtration.

In the present work, a hydrophobic membrane process-DCMD was integrated with APS for high-recovery desalting of PRO concentrate. The integrated process involved inducing and accelerating mineral precipitation by sodium hydroxide dosing, followed by 
solid-liquid separation, microfiltration and subsequent the DCMD desalting.

Membrane distillation (MD) is a thermally driven process that vapor transports through non-wetted hydrophobic porous where the driving force is the partial vapor pressure difference across the two sides of membrane pores. Compared with pressure-driven membrane processes, MD is less dependent on the initial salinity of the feed as well as a higher salt rejection. In addition, it is operated in the ordinary pressure with a less demanding in membrane's mechanical strength [19]. Thus, MD has been used in many areas such as desalination [20,21], juice concentration [22] and wastewater treatment $[23,24]$. DCMD is one of four basic configurations of $\mathrm{MD}$, and in this configuration, a feed solution at elevated temperature is in contact with one side of the membrane and colder water is in contact with the opposite side of the membrane [25]. DCMD is convenient to set up, gives high water permeation flux and appears as the best for application [26].

Accordingly, the objective of this work were to (1) evaluate the sodium dosing, seed dosage and agitating rate via small scale calcium removal tests; (2) demonstrate the integration of APS with DCMD at a laboratory-scale to achieve high water recovery; and (3) evaluate the hydrophobic stability of the PVDF membrane via the variation of the permeate flux and conductivity during $300 \mathrm{~h}$ continual running.

\section{Experimental}

\subsection{PRO concentrate and reagents}

The PRO concentrate in the experiments was obtained from the RO unit of the direct drinking water preparation system designed for the 29th Olympic Games. The RO system was operated at 50\% recovery with Beijing tap water pretreated with ozone oxidation, catalyze oxidation and active carbon filtration. The quality of PRO concentrate was shown in Table 1. Calcium carbonate powder (>99.0\%, A.C.S, Reagent, $10 \mu \mathrm{m}$ ) and quartz sand (powder, 250 mesh) were used as calcite and quarts sand seeds, respectively. All the other reagents were analytical grade.

\subsection{Analysis methods}

The solution $\mathrm{pH}$ was measured using a $\mathrm{pH}$ electrode (EC10, $\mathrm{HACH}, \mathrm{USA}$ ). Conductivity was measured using a conductivity meter (CO150, HACH, USA). Analyses of grab samples for metals, anions, alkalinity, total organic carbon and total silica were performed using methods published in Standard Methods for the Examination of Water and Wastewater (4th edition, China environmental science Press).

Table 1

Quality of the PRO concentrate.

\begin{tabular}{lc}
\hline Parameters & Values \\
\hline Turbidity $(\mathrm{NTU})$ & 0.25 \\
$\mathrm{pH}$ & 7.7 \\
Conductivity $(\mu \mathrm{S} / \mathrm{cm})$ & 960 \\
Total hardness as $\mathrm{CaCO}_{3}(\mathrm{mg} / \mathrm{L})$ & 470.7 \\
$\mathrm{Na}^{+}(\mathrm{mg} / \mathrm{L})$ & 30.0 \\
$\mathrm{~K}^{+}(\mathrm{mg} / \mathrm{L})$ & 10.9 \\
$\mathrm{Fe}^{2+}(\mathrm{mg} / \mathrm{L})$ & 0.037 \\
$\mathrm{Ca}^{2+}(\mathrm{mg} / \mathrm{L})$ & 118.2 \\
$\mathrm{Mg}^{2+}(\mathrm{mg} / \mathrm{L})$ & 43.1 \\
$\mathrm{Cl}^{-}(\mathrm{mg} / \mathrm{L})$ & 52.1 \\
$\mathrm{SO}_{4}{ }^{2-}(\mathrm{mg} / \mathrm{L})$ & 63.5 \\
$\mathrm{HCO}_{3}{ }^{-}(\mathrm{mmol} / \mathrm{L})$ & 9.25 \\
$\mathrm{CO}_{3}{ }^{2-}(\mathrm{mmol} / \mathrm{L})$ & 0.35 \\
$\mathrm{SiO}_{3}{ }^{2-}(\mathrm{mg} / \mathrm{L})$ & 11.8 \\
$\mathrm{TOC}^{2}(\mathrm{mg} / \mathrm{L})$ & 1.0 \\
\hline
\end{tabular}

\subsection{Small-scale calcium removal tests}

In order to evaluate the optimal APS operating parameters, initial small-scale calcium removal tests were carried out at room temperature $\left(25^{\circ} \mathrm{C}\right)$ by following the calcium depletion rate, using actual PRO concentrate. All the calcium removal tests were carried out in a $1 \mathrm{~L}$ beaker with a poleless speed-adjusting agitator (DDC 1850, Caframo, Canada). For each experiment, $800 \mathrm{~mL}$ RO concentrate was used. To initiate rapid precipitation, a dose of $1 \mathrm{~mol} / \mathrm{L}$ sodium hydroxide stock solution was added to the PRO concentrate to achieve the desired initial $\mathrm{pH}$ level. And calcite or quartz sand seeds were dispersed in the PRO concentrate prior to initiating the precipitation step in several experiments. The mixing speed was controlled by the agitator. The calcium concentration of grab samples was measured after being filtered $0.45 \mu \mathrm{m}$ filter.

\subsection{APS-DCMD process}

The laboratory-scale APS-DCMD setup is illustrated in Fig. 1. The APS treatment with actual PRO concentrate was conducted in a $10 \mathrm{~L}$ crystallizer. This apparatus consisted of a crystallization reactor with a conical bottom, and a poleless speed-adjusting agitator. Based on the results of the small-scale calcium removal tests, initial solution $\mathrm{pH}$ was adjusted to 10.10 , the calcite dosage was $5 \mathrm{~g} / \mathrm{L}$ and the agitating rate was $200 \mathrm{r} / \mathrm{min}$. After steady-state was reached, according to the calcium concentration, the suspended solids were allowed to settle. For $1 \mathrm{~h}$ after the initiation of the precipitation reaction, the solution was filtrated with a $2 \mu \mathrm{m}$ Nylon cartridge filter (CLD-P, ChengDeLai, China) prior to the DCMD process.

The DCMD apparatus consisted of two thermostatic cycles, the feed one and the permeate one. The feed and the permeate flowed cocurrently in the experiments, and the feed flowed through the membrane lumen side and the permeate flowed through the membrane shell side. Two magnetic pumps were used to provide the flow of the feed preheated in the thermostatic bath and the permeate cooled through the cooling coil. The feed flow rate was $0.60 \mathrm{~m} / \mathrm{s}$, whereas the permeate flow rate was $0.18 \mathrm{~m} / \mathrm{s}$ during the process. There were four thermometers equipped on both the inlet and the outlet of the feed and the permeate side. In the experiments, the inlet temperature of the feed and the permeate were kept at 50 and $20^{\circ} \mathrm{C}$, respectively. The permeate flux was measured by the overflow volume of the permeate reservoir, and the permeate conductivity was measured by an online conductivity monitor during the experimental period.

\subsection{Membrane module}

The DCMD membrane module was made by a polyester tube and two UPVC T-tubes. The outside/inside diameters of the module were $20 / 15 \mathrm{~mm}$ and the effective length of the module was $100 \mathrm{~mm}$. The module was equipped with 50 hydrophobic selfmade hollow fiber PVDF membranes. The self-made membrane was spun from PVDF/DMAc/LiCl/EtOH (12/80/5/3 wt.\%) dope. The outside/inside diameters of the membrane were $1 / 0.6 \mathrm{~mm}$, respectively. The porosity, average pore size and the membrane thickness were $80 \%, 0.15 \mu \mathrm{m}$ and $0.2 \mathrm{~mm}$, respectively. The liquid entry pressure of water (LEPw) of the membrane is $250 \mathrm{kPa}$. The total efficient area of the module was calculated for the internal diameter of hollow fiber membrane and amounted to $94.20 \mathrm{~cm}^{2}$.

\section{Results and discussion}

\subsection{Determination of the optimum softening conditions}

\subsubsection{Initial $\mathrm{pH}$}

Fig. 2 shows the calcium concentration decline at different initial $\mathrm{pH}$ without seeds. The decline expressed as the ratio $\left(\mathrm{Ca}^{2+}\right) /\left(\mathrm{Ca}^{2+}\right)_{0}$, 


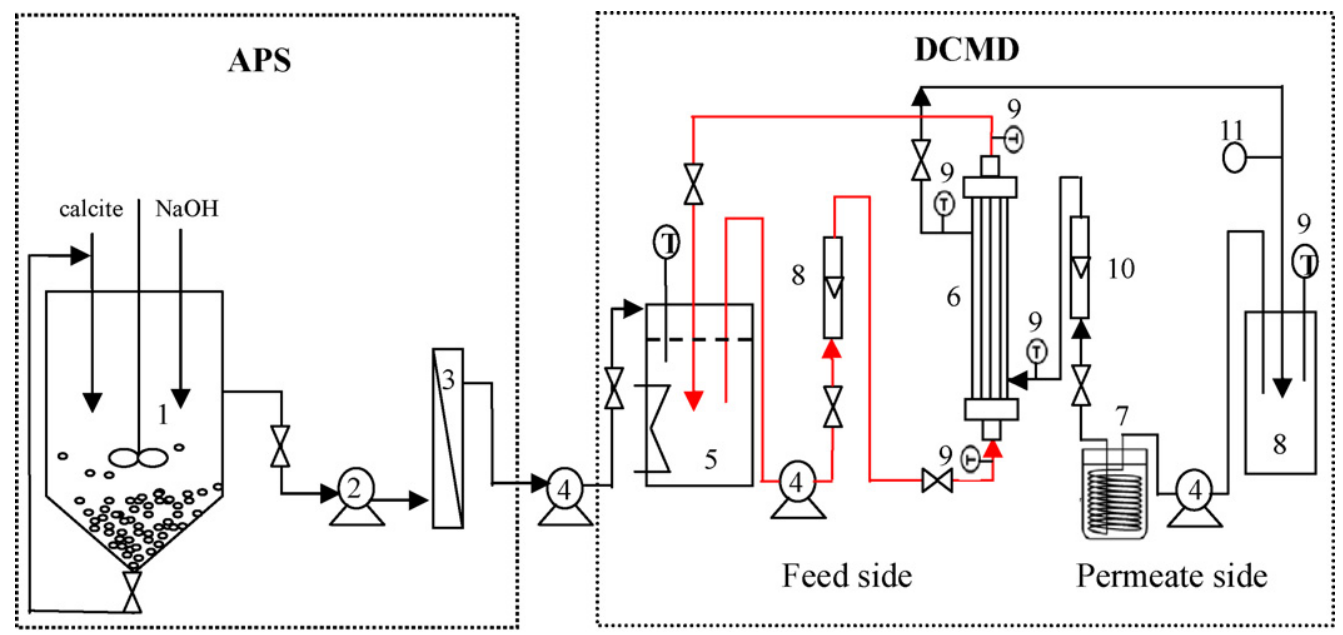

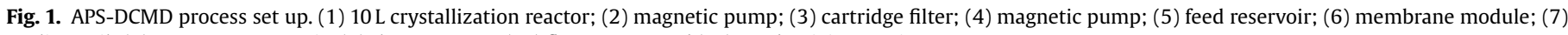
cooling coil; (8) permeate reservoir; (9) thermometer; (10) flow meter; and (11) conductivity monitor.

where $\left(\mathrm{Ca}^{2+}\right)$ is the calcium concentration at time $\mathrm{t}$ and $\left(\mathrm{Ca}^{2+}\right)_{0}$ is the initial calcium concentration. It can be noted that, in the absence of $\mathrm{NaOH}$ dosing ( $\mathrm{pH} 7.70$ ), calcium concentration of the PRO concentrate decreased by about $10 \%$ relative to the initial calcium concentration, over a period of $1.5 \mathrm{~h}$. However, once the PRO concentrate was dosed with $\mathrm{NaOH}$, the calcium concentration declined rapidly. As the solution $\mathrm{pH}$ increased from 9.10 to 11.10 , the calcium removal efficiency increased from $38 \%$ to $86 \%$, over a period of $30 \mathrm{~min}$. It is due to the deprotonation of bicarbonate ions that the concentration of $\mathrm{CO}_{3}{ }^{2-}$ was generated at higher $\mathrm{pH}$. This resulted in a higher initial calcium carbonated supersaturation and thus higher degree of $\mathrm{CaCO}_{3}$ precipitation. Also, higher initial calcium carbonate supersaturation resulted in faster precipitation kinetics as indicated by the greater rate of calcium ion depletion [16].

It should be recognized that $\mathrm{Mg}(\mathrm{OH})_{2}$ would form when solution $\mathrm{pH}$ achieved $>10.50$ according to the saturation index [16]. However, $\mathrm{Mg}(\mathrm{OH})_{2}$ precipitation is a gel-like structure with high capacity for water retention t. Therefore, in water softening processes, one typically avoids operating in the range of excessive $\mathrm{Mg}(\mathrm{OH})_{2}$ precipitation due to difficulties in solid-liquid separation and solid dewatering operations [27-29]. Therefore, initial $\mathrm{pH}$ adjustment to about 10.10, for APS treatment, was selected for evaluating for the feasibility of attaining high product water recovery.

\subsubsection{Seed selection and dosage}

The impact of calcite seed and quartz sand on precipitation softening was initially carried out with $800 \mathrm{~mL}$ PRO concentrate. The

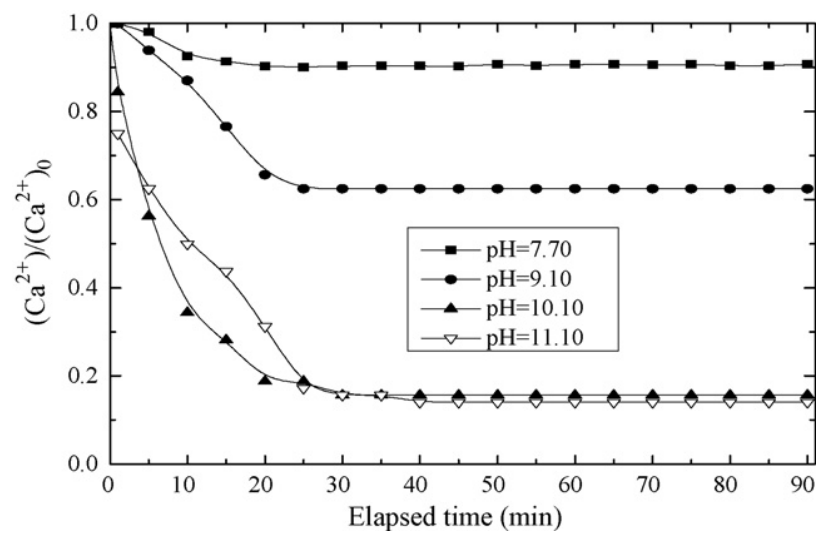

Fig. 2. Precipitation kinetics for PRO concentrate at different $\mathrm{pH}$ without seeds. initial $\mathrm{pH}$ of the PRO concentrate was 10.10 . The dosage of both the two kinds of seeds was $10 \mathrm{~g} / \mathrm{L}$, which were enough to induce the precipitation. The former experiments (Fig. 2) showed in the absence of seeding, calcium removal about $86 \%$ was attained for $\mathrm{pH} 10.10$ within $30 \mathrm{~min}$. It can be noted from Fig. 3 that $10 \mathrm{~g} / \mathrm{L}$ quartz sand and calcite resulted in even faster precipitation kinetics, within a period time of $15 \mathrm{~min}$. After steady-state was attained, $10 \mathrm{~g} / \mathrm{L}$ quartz sand result in $87 \%$ calcium removal while calcite lead to an even higher removal efficiency, as high as $94 \%$. The rapid precipitation in the above small beaker studies with alkaline $\mathrm{pH}$ adjustment and calcite seeding suggested that the precipitation softening process was kinetically controlled.

Calcium removal ration as a function of elapsed time at lower calcite seed load ( 3 and $5 \mathrm{~g} / \mathrm{L}$ ) is also showed in Fig. 3. The steadystate was approached within $15 \mathrm{~min}$ for the three calcite seed load. The results showed $3 \mathrm{~g} / \mathrm{L}$ calcite seed load resulted in $87 \%$ removal of calcite, and 5 and $10 \mathrm{~g} / \mathrm{L}$ seed load resulted in $91 \%$ calcite removal
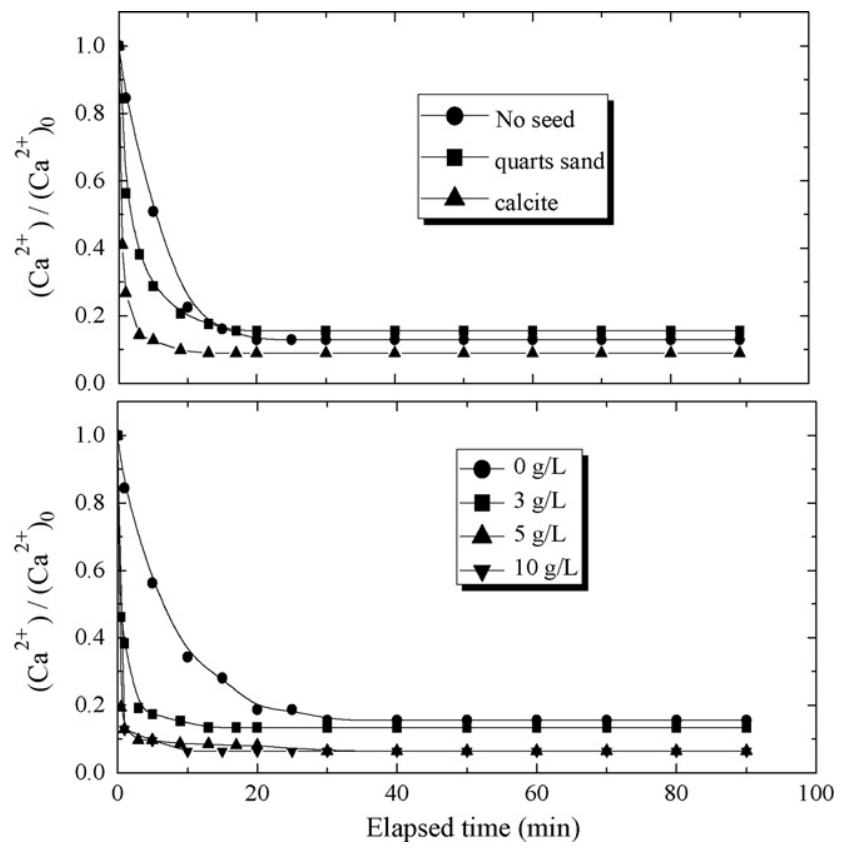

Fig. 3. Precipitation kinetics for PRO concentrate using different seeds and different calcite dosage. 
Table 2

Quality of the PRO concentrate before and after APS treatment.

\begin{tabular}{|c|c|c|c|c|c|c|}
\hline Parameters & $\mathrm{pH}$ & $\mathrm{Ca}^{2+}(\mathrm{mg} / \mathrm{L})$ & $\mathrm{Mg}^{2+}(\mathrm{mg} / \mathrm{L})$ & Total hardness as $\mathrm{CaCO}_{3}(\mathrm{mg} / \mathrm{L})$ & $\mathrm{SO}_{4}^{2-}(\mathrm{mg} / \mathrm{L})$ & $\mathrm{SiO}_{3}^{2-}(\mathrm{mg} / \mathrm{L})$ \\
\hline Before APS & 7.70 & 118.2 & 43.1 & 470.7 & 63.5 & 11.79 \\
\hline After APS & 9.90 & 9.72 & 41.2 & 195.6 & 62.8 & 11.6 \\
\hline Removal & - & $92 \%$ & $4.4 \%$ & $58.4 \%$ & $1.1 \%$ & $1.6 \%$ \\
\hline
\end{tabular}

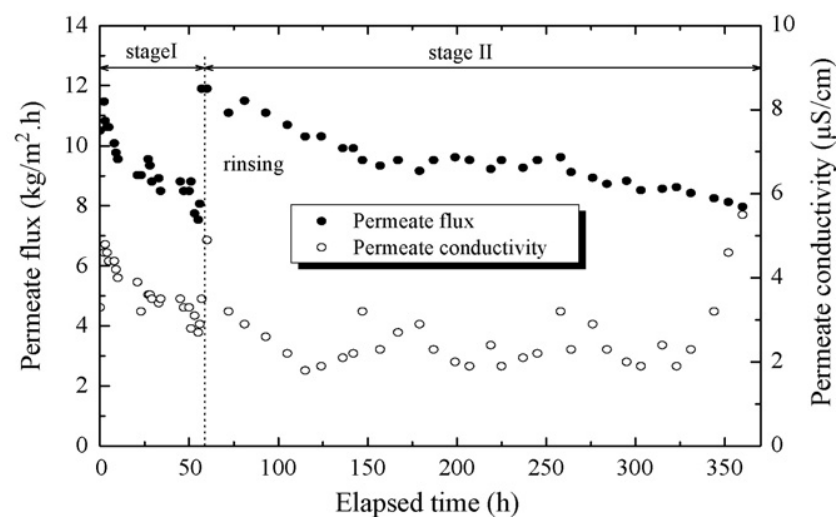

Fig. 4. Variation of permeate flux and conductivity as a function of elapsed time.

and $94 \%$ calcite removal, respectively. It is noted that operating at lower calcite seed load $(5 \mathrm{~g} / \mathrm{L})$ can also yield high calcium removal. It suggested that sufficient surface area for precipitation was achieved at this lower seed loading, so $5 \mathrm{~g} / \mathrm{L}$ was chosen to be the optimal calcite seed load.

\subsection{Performance of integrated APS-DCMD process}

Following the results of the small-scale calcium tests, a largescale APS treatment of PRO concentrate was conducted in a $10 \mathrm{~L}$ crystallizer at pH 10.10 and calcite seed load of $5 \mathrm{~g} / \mathrm{L}$. The agitation rate was kept at $200 \mathrm{r} / \mathrm{min}$. After $30 \mathrm{~min}$ of the precipitation, the suspended solids were allowed to settle for $1 \mathrm{~h}$, and then the supernatant was filtrated through a $2 \mu \mathrm{m}$ Nylon cartridge filter. Elemental analysis (Table 2) of the PRO concentrate before APS and after APS revealed that, calcium decreased from 118.20 to $9.72 \mathrm{mg} / \mathrm{L}$, with the removal efficiency about $92 \%$. In addition, the analysis indicated $4.4 \%$ removal of magnesium, $1.1 \%$ removal of sulfate and $1.6 \%$ removal of silica. There was also a measurable $58.4 \%$ removal of total hardness, which was mainly caused by the calcium depletion.

Fig. 4 illustrates the DCMD performance of the PRO concentrate before and after APS treatment. In Fig. 4 stages I, a slight increase of permeate flux from 10.82 to $11.75 \mathrm{~kg} /\left(\mathrm{m}^{2} \mathrm{~h}\right)$ was observed at the initial period of the process, just as reported in other works [30,31]. After the increase, a continual decline of the permeate flux was found. It can be noted from Fig. 4 that the permeate flux declined from initial 11.75 to $7.53 \mathrm{~kg} /\left(\mathrm{m}^{2} \mathrm{~h}\right)$ after $50 \mathrm{~h}$ running. SEM analysis of the module showed that a certain amount of deposit was found at the inlet of the module (Fig. 5(a)), however, little deposit was found at the membrane inner surface. So it can be inferred that the deposit found at the inlet of the membrane module was the major reason of the permeate flux decline. That is because the feed was pumped with magnetic pump, the deposit may cause a clogging of the feed flow channel which leads to a feed flow resistance, and therefore, cause a decline of the flow rate. A feed flow rate decrease from 0.60 to $0.45 \mathrm{~m} / \mathrm{s}$ was observed, and this decrease caused an unfavorable increase of the temperature polarization and comprises a possible reason of the observed reduction of the module efficiency. The EDS analysis showed the deposit was mainly consisted of $\mathrm{Ca}, \mathrm{C}$ and $\mathrm{O}$, and also a concentration decrease of $\mathrm{HCO}_{3}{ }^{-}$ from 9.25 to $1.43 \mathrm{mmol} / \mathrm{L}$ was found in the feed, thus it can be concluded the deposit was mainly $\mathrm{CaCO}_{3}$. The feed flow rate can entirely restored by rinsing the module with $2 \% \mathrm{HCl}$. The permeate conductivity kept decreasing and stabilized at about $3.5 \mu \mathrm{S} / \mathrm{cm}$ at last, which indicated that the PVDF membrane exhibited a stable hydrophobicity.

Fig. 4, stage II presents DCMD performance of the PRO concentrate after APS treatment. The elemental analysis (Table 2) showed that, after the APS treatment, the calcium concentration had such a significant decrease from 118.8 to $9.5 \mathrm{mg} / \mathrm{L}$ that the probability of $\mathrm{CaCO}_{3}$ and $\mathrm{CaSO}_{4}$ scaling was significantly decreased. Thus permeate flux declined only $20 \%$ after $300 \mathrm{~h}$ running, then the PRO concentrate was concentrated 40 times and the whole recovery was enhanced to $98.8 \%$. A little deposit was found at the inlet of the module (Fig. 5(b)), and the membrane inner surface was also covered with a little deposit (Fig. 5(c)). The EDS analysis showed that the deposit found at the inlet of the module and the membrane surface was both consisted of $\mathrm{Mg}, \mathrm{Si}, \mathrm{C}, \mathrm{O}$ and $\mathrm{Si}$.

The permeate conductivity kept from 2.0 to $4.0 \mu \mathrm{S} / \mathrm{cm}$ during of the process, and slightly increased to $6.0 \mu \mathrm{S} / \mathrm{cm}$ at the end. That may be associated with partial wetting phenomenon caused by large pores just as mentioned in other works [21,32,33]. Large pores inevitably exist in the membrane and lead to a low LEPw. LEPw is the minimum pressure at which water will overcome the hydrophobic forces of the membrane and will permeate pores [17]. In an integrated NF/MD demineralization process, after $90 \mathrm{~h}$ DCMD performance, the permeate conductivity was found increasing

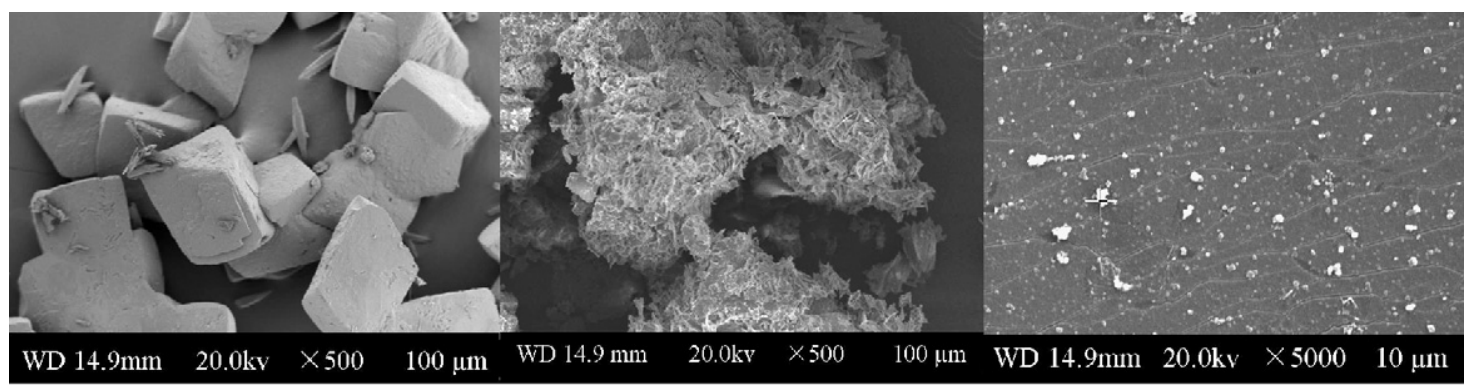

(a)

(b)

(c)

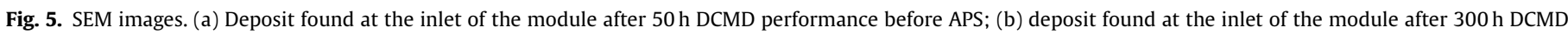
performance after APS; and (c) inner surface of the membrane after $300 \mathrm{~h}$ DCMD performance after APS. 
from 1.5 to $2.0 \mu \mathrm{S} / \mathrm{cm}$. The author inferred the phenomenon was associated with partial wettability caused by $1 \mu \mathrm{m}$ large pores [21]. Gryta pointed that a deterioration of permeate quality might occur when a partial wetting phenomenon will take place, and in the case when a wetted membrane area is not to large, MD process may be still continued [32]. However, the influence of large pores may become serious at higher concentration just like the slight permeate conductivity increase at the end of the DCMD process.

\section{Conclusions}

In the present work, accelerated precipitation softening was integrated with direct contact membrane distillation for highrecovery desalination of primary reverse osmosis concentrate. The optical solution $\mathrm{pH}$, calcite dosage and agitation rate for APS were $10.10,5 \mathrm{~g} / \mathrm{L}$ and $200 \mathrm{r} / \mathrm{min}$, respectively. Experimental results indicated that APS treatment enabled up to $92 \%$ removal of calcium, thus, $\mathrm{CaCO}_{3}$ and $\mathrm{CaSO}_{4}$ scaling was alleviated during the DCMD process. It can be noted that permeate flux declined only $20 \%$ within $300 \mathrm{~h}$ running, then the PRO concentrate was concentrated 40 times, and the whole recovery was enhanced to $98.8 \%$.

\section{Acknowledgements}

This work is supported by the National Key Technologies R\&D Program (Grant No. 2006BAJ08B05), and National Water Pollution Control R\&D Program (Grant No. 2008ZX07529-004).

\section{References}

[1] S.P. Agashichev, M.E. El-Dahshan, Reverse osmosis incorporated into existing cogenerating systems as a sustainable technological alternative for United Arab Emirates, Desalination 157 (2003) 33-49.

[2] M.D. Afonso, J.O. Jaber, M.S. Mohsen, Brackish groundwater treatment by reverse osmosis in Jordan, Desalination 164 (2004) 157-171.

[3] D. Feng, J.S.J. van Deventer, C. Aldrich, Ultrasonic defouling of reverse osmosis membranes used to treat wastewater effluents, Sep. Purif. Technol. 50 (2006) 318-323.

[4] K. Kosutic, D. Dolara, D. Aspergera, Removal of antibiotics from a model wastewater by RO/NF membranes, Sep. Purif. Technol. 53 (2007) 244-249.

[5] J. Radjenovic, M. Petrovic, F. Ventura, Rejection of pharmaceuticals in nanofiltration and reverse osmosis membrane drinking water treatment, Water Res. 42 (2008) 3601-3610.

[6] E.S. Hrayshat, Brackish water desalination by a stand alone reverse osmosis desalination unit powered by photovoltaic solar energy, Renew. Energy 33 (2008) 1784-1790.

[7] C.J. Gabelich, M.D. Williams, A. Rahardianto, High-recovery reverse osmosis desalination using intermediate chemical demineralization, J. Membr. Sci. 301 (2007) 131-141.

[8] J.K. Kimes, The regulation of concentrate disposal in Florida, Desalination 102 (1995) 87-92.
[9] J.S. Vrouwenvelder, S.A. Manolarakis, H.R. Veenendaal, Biofouling potential of chemicals used for scale control in RO and NF membranes, Desalination 132 (2000) 1-3.

[10] M. Williams, R. Evangelista, Y. Cohen, Non-thermal process for recovering reverse osmosis concentrate: process chemistry and kinetics, in: Proceedings of the 2002 AWWA Water Quality Technology Conference, Seattle, WA, 2002.

[11] AWWA, in: R.D. Letterman (Ed.), Water Quality and Treatment: A Handbook of Community Water Supplies, 5th ed., McGraw-Hill, New York, 1999.

[12] R.E. Loewenthal, H.N.S. Wiechers, G.V.R. Marais, Softening and Stabilization of Municipal Waters, Water Research Commission of South Africa, Pretoria, 1986.

[13] I. Bremere, M. Kennedy, P. Michel, R. van Emmerik, G.J. Witkamp, J. Schippers, Controlling scaling in membrane filtration systems using a desupersaturation unit, Desalination 124 (1999) 51-62.

[14] G.J.G. Juby, C.F. Schutte, Membrane life in a seeded-slurry reverse osmosis system, Water S.A. 26 (2000) 239-248.

[15] Y. Oren, V. Katz, N.C. Daltrophe, Improved compact accelerated precipitation softening (CAPS), Desalination 139 (2001) 155-159.

[16] A. Rahardianto, J. Gao, C.J. Gabelich, High recovery membrane desalting of lowsalinity brackish water: integration of accelerated precipitation softening with membrane RO, J. Membr. Sci. 289 (2007) 123-137.

[17] J. Gilron, D. Chaikin, N. Daltrophe, Demonstration of CAPS pretreatment of surface water for RO, Desalination 127 (2000) 271-282.

[18] J. Gilron, N. Daltrophe, M. Waissman, Comparison between compact accelerated precipitation softening (CAPS) and conventional pretreatment in operation of brackish water reverse osmosis (BWRO), Ind. Eng. Chem. Res. 44 (2005) 5465-5471.

[19] K.W. Lawson, D.R. Lloyd, Membrane distillation, J. Membr. Sci. 124 (1997) 1-25

[20] S.T. Hsu, K.T. Cheng, J.S. Chiou, Seawater desalination by direct contact membrane distillation, Desalination 143 (2002) 279-287.

[21] K. Karakulski, M. Gryta, Water demineralization by NF/MD integrated process, Desalination 177 (2005) 109-119.

[22] K.B. Petrotos, H.N. Lazarides, Osmotic concentration of liquid foods, J. Food Eng. 49 (2001) 201-206.

[23] M. Gryta, K. Karakulski, The application of membrane distillation for the concentration of oil-water emulsions, Desalination 121 (1999) 23-29.

[24] T.G. Zakrzewska, M. Harasimowicz, A.G. Chmielewski, Membrane processes in nuclear technology-application for liquid radioactive waste treatment, Sep. Purif. Technol. 22 (2001) 617-625.

[25] T.Y. Cath, V.D. Adams, A.E. Childress, Experimental study of desalination using direct contact membrane distillation: a new approach to flux enhancement, J. Membr. Sci. 228 (2004) 5-16.

[26] J. Phattaranawik, R. Jiraratananon, Direct contact membrane distillation: effect of mass transfer on heat transfer, J. Membr. Sci. 188 (2001) 137-143.

[27] S.R. Roalson, J. Kweon, D.F. Lawler, Enhanced softening: effects of lime dose and chemical additions, J. Am. Water Works Assoc. 95 (2003) 97-109.

[28] S.J. Randtke, C.E. Thiel, M.Y. Liao, Removing soluble organic contaminants by lime-softening, J. Am. Water Works Assoc. 74 (1982) 192-202.

[29] P.F. Chao, P. Westerhoff, Assessment, Optimization of chemical and physicochemical softening processes, J. Am. Water Works Assoc. 94 (2002) 109-119.

[30] A.M. Barbe, P.A. Hogan, R.A. Johnson, Surface morphology changes during initial usage of hydrophobic micro-porous polypropylene membranes, J. Membr. Sci. 172 (2000) 149-156.

[31] M. Gryta, Long-term performance of membrane distillation process, J. Membr Sci. 265 (2005) 153-159.

[32] M. Gryta, Influence of polypropylene membrane surface porosity on the performance of membrane distillation process, J. Membr. Sci. 287 (2007) 67-78.

[33] D. Qu, J. Wang, D. Hou, Experimental study of arsenic removal by direct contact membrane distillation, J. Hazard. Mater. 163 (2009) 874-879. 